\title{
COVID-19 and the long-term cardio-respiratory and metabolic health complications
}

\author{
Ruth Ashton ${ }^{1, *}$, Paul Ansdell ${ }^{2}$, Emily Hume ${ }^{2}$, Tom Maden-Wilkinson ${ }^{3}$, Declan Ryan ${ }^{4}$, \\ Esme Tuttiett ${ }^{5}$, Mark Faghy ${ }^{1}$ \\ ${ }^{1}$ Human Sciences Research Centre, University of Derby, DE22 1GB Derby, UK \\ ${ }^{2}$ Department of Sport, Exercise and Rehabilitation, Northumbria University, NE1 8ST Newcastle upon Tyne, UK \\ ${ }^{3}$ Advanced Well-being Research Centre, Sheffield Hallam University, S9 3TU Sheffield, UK \\ ${ }^{4}$ Centre for Physical Activity and Life Sciences, University of Northampton, NN1 5PH Northampton, UK \\ ${ }^{5}$ Department of Oncology and Metabolism, The Medical School, University of Sheffield, S19 2RX Sheffield, UK \\ *Correspondence: r.ashton@derby.ac.uk (Ruth Ashton) \\ Academic Editor: Peter Kokkinos \\ Submitted: 15 December 2021 Revised: 7 January 2022 Accepted: 12 January 2022 Published: 9 February 2022
}

\begin{abstract}
Severe acute respiratory syndrome coronavirus type-2 (SARS-CoV-2) transmission continues to impact people globally. Whilst the acute symptoms and management strategies are well documented, millions of people globally are experiencing a prolonged and debilitating symptom profile that is reported to last months and even years. COVID-19 is a multi-system disease however the magnitude of the effects and its associated legacy is presently not well understood. Early reports indicate that multidisciplinary approaches between clinical and non-clinical entities are needed to provide effective and rehabilitative patient support pathways and restore pre-COVID-19 quality of life and functional status. Accordingly, this review provides a summary of the impact on cardiovascular, inflammatory, respiratory, and musculoskeletal function following an acute COVID-19 infection along with the prolonged effects of long-COVID.
\end{abstract}

Keywords: COVID-19; long-COVID; cardiorespiratory; cardiometabolic; recovery; rehabilitation

\section{Introduction}

SARS-CoV-2 is a novel coronavirus that surfaced in late 2019 now commonly referred to as COVID-19. The virus resulted in a worldwide pandemic of a disease named by the World Health Organisation (WHO) as COVID-19. The COVID-19 pandemic continues to infect many people worldwide with extreme symptoms now being well documented [1-4]. However, the long-term effects on those infected by the virus remain largely unknown. Whilst a series of longitudinal investigations are underway to increase the knowledge and understanding, reports highlight that sustained transmission and emerging variants continue to cause global challenges to healthcare providers. Currently, it is estimated that of those infected with COVID19 in the UK, one in ten people will experience prolonged symptoms lasting months to years including fatigue, breathlessness, neurological deconditioning [5]. These effects are referred to as Post-Acute Sequelae of SARS-CoV-2 infection colloquially termed 'long-COVID' with the magnitude and the associated legacy impacts and the burden to population health and wellbeing being presently not understood in its entirety. Whilst the authors acknowledge the evident and documented favourable female sex bias in COVID-19 infection and severity, the need to understand the mechanisms and causal relationships (e.g., comorbidities and underlying health status) requires further investigation [6] and is outside of the scope of this current review.

\section{Cardiovascular function}

Initially, COVID-19 was thought to primarily be an acute respiratory distress syndrome (ARDS) however, it has since become clear that COVID-19 is in fact a multiple organ disease. Cardiovascular disease (CVD) remains the leading cause of morbidity and mortality globally [7] and medication prescribed to reduce the risk of CVD could increase the susceptibility to or the severity of a COVID19 infection [8]. It also appears that COVID-19 infection can promote cardiovascular disorders. The virus enters host cells through the binding of the spike protein to Angiotensin converting enzyme 2 (ACE-2) on pulmonary epithelial cells causing damage to the lungs as well as directly binding to vascular endothelial cells of other organs, such as the kidneys and heart $[9,10]$. It is possible that, due to the mediating effects of ACE-2 on blood pressure, those with hypertension could have some dysregulation of ACE-2 function therefore predisposing individuals to severe conditions and mortality [11]. It has also been suggested that the occurrence of cardiovascular events in those with COVID-19 is caused by inflammation and vascular remodelling brought about by endothelial dysfunction $[9,12]$. Such dysfunction is due to 'cytokine and coagulation storms' that can compromise the integrity and physiological anti-thrombotic and anti-inflammatory properties of the endothelium within vessels [13]. 
Data suggests an increased risk of severe complications and mortality in those who contract COVID-19 with pre-existing CVD or who present with one or more risk factors such as hypertension, diabetes mellitus, hypercholesterolaemia, or obesity [14-16]. For example, a metaanalysis performed in China suggested that mortality in those with pre-existing CVD and infected with COVID-19 was around $11 \%$ [17]. In addition, a report of 393 patients hospitalised with COVID-19 in the USA demonstrated that $\sim 50 \%$ of patients had underlying hypertension ( $54 \%$ of ventilated patients), $36 \%$ were obese ( $43 \%$ of ventilated patients), $25 \%$ had diabetes mellitus ( $28 \%$ of ventilated patients) and $14 \%$ were diagnosed with coronary artery disease (19\% of ventilated patients) [18]. The high prevalence of obesity amongst those hospitalised with COVID-19 reported here was also deemed to be a considerable risk factor for respiratory failure, prompting the need for mechanical ventilation.

It appears that a COVID-19 infection promotes the development of cardiovascular disorders including myocardial injury, myocarditis, arrhythmias, acute coronary syndrome, and venous thromboembolism $[8,13,14,19]$. Elevated cardiac troponin (cTn) levels are evident in 8-62\% of hospitalised patients with COVID-19 and are suggestive of myocardial injury alongside being associated with greater disease severity, need for mechanical ventilation, and mortality [19-22]. Along with biomarker evidence, echocardiographic abnormalities are also commonly reported. Such abnormalities include right ventricular dysfunction (26.3\%), left ventricular wall motion abnormalities (23.7\%), global left ventricular dysfunction (18.4\%), diastolic dysfunction (13.2\%), and pericardial effusion (7.2\%) [21]. In addition, it appears that coronary artery calcium and total thoracic calcium obtained via chest computed tomography (CT) on admission of COVID-19 patients in hospital, could be used to help with risk stratification and help assess patients' mortality risk [23]. It has been suggested that drugs such as canakinumab, previously used as an interleukin- $1 \beta$ blocking agent in cancer patients, can significantly reduce mortality rate and CVD in patients deemed to be at a higher risk of mortality [24].

The severity, extent, and long-term cardiovascular effects of COVID-19 and its treatments are yet to be understood entirely. However, there is evidence of cardiovascular involvement post-COVID-19 infection. Puntmann et al. [25] reported cardiac involvement in $78 \%$, and ongoing inflammation in $60 \%$ of patients $(n=100)$ in the months following COVID-19 infection. It was also evident that various cardiac symptoms were common with atypical chest pain (17\%), palpitations $(20 \%)$, and dyspnoea and exhaustion (36\%) all being reported [25]. For those with CVD, long-COVID is of concern due to its association with high morbidity and exacerbation of underlying cardiovascular disorders. Studies examining patients with long-COVID have reported dyspnoea, joint pain and muscle weakness, chest pain, sleep difficulties and reduced quality of life [26,27]. What remains unclear, is the link between cardiac involvement and insult as a result of a COVID-19 infection and the symptoms evident in those with long COVID.

\section{Blood biomarkers}

The clustering of cardiovascular risk factors (hyperglycaemia, obesity, dyslipidaemia, and hypertension) is termed metabolic syndrome [28]. Although the presence of these components is associated with adverse outcomes of COVID-19 [29-36], there is limited evidence on the risk of long-term complications, with most finding no increased risk of long-COVID [37-39]. Conversely, infection with COVID-19 does appear to increase the risk of future development of cardio-metabolic issues such as myocardial inflammation and substantial impairment within multiple organs (e.g., lungs, liver, pancreas) [25,40-42].

The components of metabolic syndrome can stimulate the dysregulation of the Renin-Angiotensin-Aldosterone System, modulated by ACE-2, leading to an increased presence of Angiotensin II. The binding of Angiotensin II to Angiotensin II type I receptors can be a stimulus for cardiovascular insult, such as endothelial dysfunction, thrombosis, chronic inflammation [19,43]. COVID-19 binds to ACE-2 [44] and enters cells via ACE-2 receptors present on the cells of multiple organs [45]. The cardioprotective role of ACE-2, and the binding of COVID-19 to ACE-2, has created uncertainties in the susceptibility to COVID-19 in patients prescribed ACE inhibitors [46], whilst suggestions of pharmaceutical discontinuation should not be made without evidence of an increased risk of infection in this population [47]. That being said, a study by Wang and colleagues suggests that ACE inhibitors are safe for COVID19 patients and can also help in the treatment of COVID-19 induced pneumonia and can be used in line with relevant guidance [48]. The influence of Angiotensin II on COVID19 severity has been demonstrated in a cross-sectional study that evidenced higher concentrations of Angiotensin II in critically-ill COVID-19 patients, in comparison to mildlyill and controls [49]. In populations with components of metabolic syndrome, the concentration of Angiotensin II is elevated and the subsequent elevation of Angiotensin II due to COVID-19 infection will likely exacerbate cardiovascular, respiratory, and metabolic complications [50].

COVID-19 stimulates an inflammatory response with interleukin-6 (IL-6), C-reactive protein (CRP), and tumour necrosis factor-alpha (TNF- $\alpha$ ) [51-54]. The chronic presence of IL-6 and TNF- $\alpha$ within the endothelium stimulates vascular smooth muscle cell migration from the Media to the Intima [55,56], contributing to arterial wall thickening and atherosclerotic plaque formation. Furthermore, the maximum value of IL- 6 and CRP have predicted respiratory failure [57]. On 6th July 2021, the World Health Organisation updated its patient care guideline to include IL-6 receptor blockers for severely or critically ill COVID-19 patients 
[58] as administration of these drugs reduces the need for mechanical ventilation (30 fewer per 1000 patients), length of hospital stay (4.3 days fewer), but the association with mortality was less clear (15 fewer per 1000 patients) [59].

It appears that pre-existing metabolic syndrome components do not appear to be predictors of long-COVID, but the SARS-CoV-2 infection does appear to increase the risk of future cardiometabolic complications. It seems that part of the pathophysiology surrounding this increased risk of future cardiometabolic issues could to due to the disruption in the Renin-Angiotensin-Aldosterone System and systemic inflammatory responses. Further longitudinal research will be required to determine the need and efficacy of (non)pharmaceutical intervention to manage cardiometabolic implications of COVID-19 infection [60].

\section{Respiratory function}

The respiratory system is the front-line of the COVID19 infection, with the respiratory tract epithelium the key entry point upon inhalation [61]. The respiratory symptoms and outcomes of COVID-19 are diverse, with many displaying mild upper respiratory tract symptoms, however, some patients develop more severe illness, commonly viral pneumonia, leading to ARDS relating to poor health outcomes and/or mortality [62]. Data on the short-term respiratory sequelae is still emerging, and longer-term follow-up studies remain scarce. However, from the limited available data, 188 patients (from 1370 pulmonary CT scans) identified the presence of pleural effusion which was linked to increased risk of cardio-respiratory complications and in hospital mortality [63]. Whilst more detailed investigations and cohort analysis are needed, the presence of pulmonary effusion in hospitalized patients, might serve as a clinical indicator to COVID-19 severity and post-COVID-19 outcomes. Early data, and that from previous coronavirus outbreaks, indicates that long-term respiratory complications and a profound and complex symptomology are likely to persist in some patients [64].

Current evidence on the acute effects of COVID-19 shows reduced pulmonary diffusing capacity (DLco) as the key impairment following infection. This is largely associated with disease severity, with abnormally low DLco ( $<80 \%$ predicted) reported in approximately $60 \%$ of patients with severe disease, $32 \%$ in moderate disease and $20 \%$ in mild disease [65]. COVID-19 appears to have little impact on spirometry measures, with lung volumes close to normative values, particularly in those with milder disease [66]. At 3 months post-infection, chronic dyspnoea is reported in approximately half of the patients and is associated with greater restriction on spirometry, lower DLco, reduced functional capacity and greater desaturation during exertion, compared to those without persistent dyspnoea [67], suggestive of an underlying physiological mechanism that is responsible for this.

As the pandemic ensues, studies looking at the longer- term ( $>3$ months) implications of COVID-19 are beginning to emerge $[26,68,69]$. The UK-based multi-centre PHOSP-COVID study [60,69] concluded that 5-months post-hospitalisation, recovery was only $29 \%$, with $94 \%$ of patients experiencing prolonged symptom profiles. At 6 months, studies have shown that impaired DLco $(<80 \%)$ persists, with low DLco present in $30-55 \%$ of patients $[26,68,69]$. However, significant improvements in DLco have been shown 6-12 months post-hospitalisation, with evidence that women are at higher risk of persistent lung diffusion impairment [68]. In this 12-month follow-up study, exercise capacity improved significantly over time, however persistent physiological and CT scan abnormalities were evident in a sub-group of patients. Persistent radiological abnormalities included interstitial thickening and reticular opacity, suggestive of evolving fibrosis [68]. Experience from Middle East respiratory syndrome (MERS) and SARS-CoV-1 indicates that fibrotic disease may be an outcome of concern from COVID-19 [70]. Evidence from SARS-CoV-1 showed that $4.6 \%$ of patients had interstitial lung abnormalities at 15 years, with the greatest recovery from interstitial lung damage occurring within the first two years following infection [71].

The extent of pulmonary function and physical impairment following COVID-19 remains unclear. In addition to the paucity of long-term follow-up data following COVID-19 infection, most data report the health consequences of hospitalised individuals, thus more research on long-COVID and in non-hospitalised individuals is crucial [72] to inform and meet the broad needs of patients and to mitigate against the impending impact upon healthcare systems, the economy and society.

\section{Skeletal muscle}

It is important to recognise the integrative pathophysiological processes following COVID-19 infection and subsequent long-COVID. Cardiorespiratory fitness is a key predictor of functional capacity, quality of life, and a strong predictor of mortality $[73,74]$. Aerobic capacity, quantified by maximal oxygen consumption $\left(\mathrm{VO}_{2 p e a k}\right)$, and ventilatory efficiency, is quantified by the minute ventilation/carbon dioxide production $\left(\mathrm{VE} / \mathrm{VCO}_{2}\right)$ slope, are two established measures obtained through cardio-pulmonary exercise testing and several initial studies to date have reported the impact of COVID-19 on both [75]. Indeed, at discharge from hospitalisation, $\mathrm{VO}_{2 p e a k}$ is impaired in COVID patients, which has been attributed to a peripheral oxygen extraction limitation, rather than central impairment [76]. Similarly, investigations at 3 months [77] and 11 months post-hospitalisation [78] have shown impaired $\mathrm{VO}_{2 \text { peak }}$ and early attainment of ventilatory threshold alongside 'normal' pulmonary function. It is wellestablished that $\mathrm{VO}_{2 \text { peak }}$ is determined by the delivery and utilisation of oxygen [79]. The latter depends on factors within the periphery that mediate the pathway of oxygen 
from haemoglobin to mitochondria, as well as mitochondrial function itself [80]. Long-COVID symptoms could be underpinned by dysfunction in the pathway of oxygen from the blood to mitochondria [75]. Strategies are needed to augment impaired physiological processes and also require detailed investigation. Cardiovascular exercise is known to be a potent stimulus for mitochondrial biogenesis and improving mitochondrial function [81]. The optimal prescription and inclusion of exercise in long-COVID patients must be considered with the balance of factors such as reduced exercise capacity and tolerance as well as post-exertional malaise [82]. As highlighted by Twomey et al. [82], and enforced here, exercise is not the route to recovery for all patients in other diseases, such as cancer or chronic fatigue syndrome; therefore, careful consideration and appropriate measures should be taken when prescribing exercise as a rehabilitative tool in long-COVID patients.

The hyperinflammatory state and altered cardiorespiratory function result in excessive fatigue or postexertional malaise that is being reported in patients with long-COVID. In conditions where post-exertional malaise and excessive fatigue are characteristics such as myalgic encephalomyelitis (ME)/chronic fatigue syndrome (CFS), there is a demonstrable reduction in $\mathrm{VO}_{2 p e a k}$ in the days following testing with an altered metabolic [83] and inflammatory response to exercise observed [84,85]. There is a strong link between ME/CFS and autonomic nervous system abnormalities. The autonomic nervous system plays a vital role in the regulation of the whole-body homeostasis and so any disruption can have a significant effect on multiple bodily systems [86]. There is some evidence to suggest that long-COVID may also include autonomic dysfunction therefore aggravating some cardio-respiratory and metabolic complications therefore supporting the multisystem nature of COVID-19 [86,87]. A shift in energy system contribution to adenosine triphosphate (ATP) resynthesis is common in viral infections [88], with an increased rate of glycolysis and downregulation of oxidative phosphorylation typically observed [89]. Impaired oxidative phosphorylation likely occurs during the acute COVID-19 infection period. During exercise, this can lead to the accumulation of deleterious metabolites which impair the contractile function of skeletal muscle, but additionally, a shift in the inflammatory status of muscle. There is a need to increase mechanistic insight into mitochondrial (dys)function in long COVID to test this hypothesis although, it does seem to be the case in other diseases with similar symptomatology such as ME [83].

COVID-19 induces a systemic hyperinflammatory state causing multi-organ damage via the 'cytokine storm' [90,91]. In addition, viral infections increase mitochondrial production of reactive oxygen species and suppress endogenous anti-oxidant systems [92]. Combined, this hyperinflammatory state leads to cachexia and sarcopenia [93,94]. The resulting loss of muscle tissue alongside disuse atro- phy results in premature loss of muscle strength impeding physical function and potentially future independence of patients with long-COVID. Taking approaches from combating age-related and disease-related muscle atrophy (e.g., nutrition and exercise) could provide beneficial adaptations in preventing neuromuscular decline. The National Institute for Health Care and Excellence (NICE) recommends that following COVID-19 infection, initiating progressive rehabilitation programmes within the 30 days will lead to optimal impacts and enhancement of recovery [95]. These programmes should be multidisciplinary and holistic, but with respect to enhancing musculoskeletal health, should primarily focus on rectifying any muscle atrophy that has occurred with consideration to excessive fatigue or postexertional malaise $[45,74]$.

\section{Conclusions}

The results of observational studies highlight that long-COVID patients report persistent and debilitating symptoms that impact recovery, quality of life and broader economic and social activities [96]. A recent scoping review reports that patients highlighted $>100$ different symptoms with varying severity [97] broadly defined in the areas of cardiovascular [98], pulmonary [99] and respiratory [26], pain [100], fatigue [101], psychological and cognitive disorders [102], sensory impairment [103], functional impairment [104] alongside general infection symptoms (e.g., nausea and fever). Whilst these studies have identified commonly reported symptoms, it is clear that patient experiences are broad and there is a need for longitudinal approaches to determine the prevalence and fluctuation of symptom exacerbation. The information obtained from such approaches should be used in conjunction with the lived experiences of patients in the design and development of COVID-19 specific support pathways that are developed using a non-pharmacological and rehabilitative basis that can be used to restore pre-COVID-19 functional status.

What is increasingly apparent is that multiple agencies will need to come together in interdisciplinary approaches to support long-COVID patients. To be effective the patient support pathways will undoubtedly be as complex as the symptomology, creating a unique challenge for clinical (e.g., primary care) and non-clinical entities (e.g., community health services and academic research institutions) to work collaboratively in the interest of improved patient outcomes. With long-COVID affecting $~ 57 \%$ of confirmed cases in the 6-months post-infection [105], pressure on clinical services will continue to grow with a broad impact upon all clinical areas. In a previous paper, the role and importance of utilising complementary expertise, knowledge and resource from sports medicine and the exercise sciences were highlighted [106,107]. As the prevalence of longCOVID increases globally and the need for complex and multi-faceted support pathways is apparent. There is undoubtedly a need to look at broader opportunities to facili- 
tate service delivery and address existing and longstanding issues with morbidity and functional capacity.

\section{Author contributions}

RA and MF designed the paper. RA, PA, EH, TM$\mathrm{W}, \mathrm{DR}, \mathrm{ET}$ and MF contributed to the writing and editorial changes in the manuscript. All authors read and approved the final manuscript.

\section{Ethics approval and consent to participate}

\author{
Not applicable.
}

\section{Acknowledgment}

We would like to express our gratitude to all those who helped us during the writing of this manuscript. Thanks to all the peer reviewers for their opinions and suggestions.

\section{Funding}

This research received no external funding.

\section{Conflict of interest}

The authors declare no conflict of interest. Mark Faghy is serving as one of the Guest editors of this journal. We declare that Mark Faghy had no involvement in the peer review of this article and has no access to information regarding its peer review. Full responsibility for the editorial process for this article was delegated to Peter Kokkinos.

\section{References}

[1] Chen N, Zhou M, Dong X, Qu J, Gong F, Han Y, et al. Epidemiological and clinical characteristics of 99 cases of 2019 novel coronavirus pneumonia in Wuhan, China: a descriptive study. The Lancet. 2020; 395: 507-513.

[2] Huang C, Wang Y, Li X, Ren L, Zhao J, Hu Y, et al. Clinical features of patients infected with 2019 novel coronavirus in Wuhan, China. The Lancet. 2020; 395: 497-506.

[3] Wang D, Hu B, Hu C, Zhu F, Liu X, Zhang J, et al. Clinical Characteristics of 138 Hospitalized Patients with 2019 Novel Coronavirus-Infected Pneumonia in Wuhan, China. The Journal of the American Medical Association. 2020; 323: 1061.

[4] Zhu N, Zhang D, Wang W, Li X, Yang B, Song J, et al. A Novel Coronavirus from Patients with Pneumonia in China, 2019. New England Journal of Medicine. 2020; 382: 727-733.

[5] Mahase E. Covid-19: What do we know about "long covid"? British Medical Journal. 2020; 370: m2815.

[6] Cereda A, Toselli M, Palmisano A, Vignale D, Leone R, Nicoletti $\mathrm{V}$, et al. The hidden interplay between sex and COVID-19 mortality: the role of cardiovascular calcification. GeroScience. 2021; 43: 2215-2229.

[7] World Health Organization cardiovascular disease risk charts: revised models to estimate risk in 21 global regions. Lancet Glob Health. 2019; 7: e1332-e1345.

[8] Nishiga M, Wang DW, Han Y, Lewis DB, Wu JC. COVID-19 and cardiovascular disease: from basic mechanisms to clinical perspectives. Nature Reviews Cardiology. 2020; 17: 543-558.

[9] Liu H, Wang Z, Sun H, Teng T, Li Y, Zhou X, et al. Thrombosis and Coagulopathy in COVID-19: Current Understanding and Implications for Antithrombotic Treatment in Patients Treated With Percutaneous Coronary Intervention. Frontiers in Cardiovascular Medicine. 2021; 7: 599334.
[10] Lu R, Zhao X, Li J, Niu P, Yang B, Wu H, et al. Genomic characterisation and epidemiology of 2019 novel coronavirus: implications for virus origins and receptor binding. Lancet. 2020; 395: 565-574.

[11] Del Turco S, Vianello A, Ragusa R, Caselli C, Basta G. COVID19 and cardiovascular consequences: is the endothelial dysfunction the hardest challenge? Thrombosis Research. 2020; 196: 143-151.

[12] Deanfield JE, Halcox JP, Rabelink TJ. Endothelial function and dysfunction: testing and clinical relevance. Circulation. 2007; 115: 1285-1295.

[13] Zheng Y, Ma Y, Zhang J, Xie X. COVID-19 and the cardiovascular system. Nature Reviews Cardiology. 2020; 17: 259-260.

[14] Cenko E, Badimon L, Bugiardini R, Claeys MJ, De Luca G, de Wit $\mathrm{C}$, et al. Cardiovascular disease and COVID-19: a consensus paper from the ESC Working Group on Coronary Pathophysiology \& Microcirculation, ESC Working Group on Thrombosis and the Association for Acute CardioVascular Care (ACVC), in collaboration with the European Heart Rhythm Association (EHRA). Cardiovascular Research. 2021; 117: 2705-2729.

[15] Madjid M, Safavi-Naeini P, Solomon SD, Vardeny O. Potential Effects of Coronaviruses on the Cardiovascular System: A Review. JAMA Cardiology. 2020; 5: 831.

[16] Clerkin KJ, Fried JA, Raikhelkar J, Sayer G, Griffin JM, Masoumi A, et al. COVID-19 and Cardiovascular Disease. Circulation. 2020; 141: 1648-1655.

[17] CDC Weekly C. The Epidemiological Characteristics of an Outbreak of 2019 Novel Coronavirus Diseases (COVID-19) China, 2020. China CDC Weekly. 2020; 2: 113-122.

[18] Goyal P, Choi JJ, Pinheiro LC, Schenck EJ, Chen R, Jabri A, et al. Clinical Characteristics of Covid-19 in New York City. New England Journal of Medicine. 2020; 382: 2372-2374.

[19] Chung MK, Zidar DA, Bristow MR, Cameron SJ, Chan T, Harding CV, et al. COVID-19 and Cardiovascular Disease. Circulation Research. 2021; 128: 1214-1236.

[20] Sandoval Y, Januzzi JL, Jaffe AS. Cardiac Troponin for Assessment of Myocardial Injury in COVID-19: JACC Review Topic of the Week. Journal of the American College of Cardiology. 2020; 76: 1244-1258.

[21] Lim GB. Myocardial injury in patients with COVID-19. Nature Reviews Cardiology. 2020; 17: 454-454.

[22] Shi S, Qin M, Shen B, Cai Y, Liu T, Yang F, et al. Association of Cardiac Injury with Mortality in Hospitalized Patients with COVID-19 in Wuhan, China. JAMA Cardiology. 2020; 5: 802.

[23] Giannini F, Toselli M, Palmisano A, Cereda A, Vignale D, Leone $\mathrm{R}$, et al. Coronary and total thoracic calcium scores predict mortality and provides pathophysiologic insights in COVID-19 patients. Journal of Cardiovascular Computed Tomography. 2021; 15: 421-430.

[24] Quagliariello V, Paccone A, Iovine M, Cavalcanti E, Berretta $\mathrm{M}$, et al. Interleukin-1 blocking agents as promising strategy for prevention of anticancer drug-induced cardiotoxicities: possible implications in cancer patients with COVID-19. European Reviews for Medical and Pharmacological Sciences. 2021; 25: 6797-6812.

[25] Puntmann VO, Carerj ML, Wieters I, Fahim M, Arendt C, Hoffmann $\mathrm{J}$, et al. Outcomes of Cardiovascular Magnetic Resonance Imaging in Patients Recently Recovered from Coronavirus Disease 2019 (COVID-19). JAMA Cardiology. 2020; 5: 1265.

[26] Huang C, Huang L, Wang Y, Li X, Ren L, Gu X, et al. 6-month consequences of COVID-19 in patients discharged from hospital: a cohort study. The Lancet. 2021; 397: 220-232.

[27] Carfì A, Bernabei R, Landi F. Persistent Symptoms in Patients after Acute COVID-19. The Journal of the American Medical Association. 2020; 324: 603. 
[28] Huang PL. A comprehensive definition for metabolic syndrome. Disease Models \& Mechanisms. 2009; 2: 231-237.

[29] Li X, Xu S, Yu M, Wang K, Tao Y, Zhou Y, et al. Risk factors for severity and mortality in adult COVID-19 inpatients in Wuhan. Journal of Allergy and Clinical Immunology. 2020; 146: 110 118

[30] Zheng Z, Peng F, Xu B, Zhao J, Liu H, Peng J, et al. Risk factors of critical \& mortal COVID-19 cases: a systematic literature review and meta-analysis. Journal of Infection. 2020; 81: e16e25.

[31] Yang J, Hu J, Zhu C. Obesity aggravates COVID-19: a systematic review and meta-analysis. Journal of Medical Virology. 2021; 93: 257-261.

[32] Chen T, Wu D, Chen H, Yan W, Yang D, Chen G, et al. Clinical characteristics of 113 deceased patients with coronavirus disease 2019: retrospective study. British Medical Journal. 2020; 368: m1091.

[33] Zhou F, Yu T, Du R, Fan G, Liu Y, Liu Z, et al. Clinical course and risk factors for mortality of adult inpatients with COVID19 in Wuhan, China: a retrospective cohort study. The Lancet. 2020; 395: 1054-1062.

[34] Wang SY, Singh A, Eder MD, Vadlamani L, Lee AI, Chun HJ, et al. Association of obesity with venous thromboembolism and myocardial injury in COVID-19. Obesity Research \& Clinical Practice. 2021; 15: 512-514.

[35] Yates T, Summerfield A, Razieh C, Banerjee A, Chudasama Y, Davies MJ, et al., Obesity, Ethnicity, and Covid-19 Mortality: A population-based cohort study of 12.6 Million Adults in England. MedRxiv. 2021. (in press)

[36] Yates T, Zaccardi F, Islam N, Razieh C, Gillies CL, Lawson CA, et al. Obesity, chronic disease, age, and in-hospital mortality in patients with covid-19: analysis of ISARIC clinical characterisation protocol UK cohort. BMC Infectious Diseases. 2021; 21: 717

[37] Hirschtick JL, Titus AR, Slocum E, Power LE, Hirschtick RE, Elliott MR, et al. Population-based estimates of post-acute sequelae of SARS-CoV-2 infection (PASC) prevalence and characteristics. Clinical Infectious Diseases. 2021; 73: 2055-2064.

[38] Peghin M, Palese A, Venturini M, De Martino M, Gerussi V, Graziano E, et al. Post-COVID-19 symptoms 6 months after acute infection among hospitalized and non-hospitalized patients. Clinical Microbiology and Infection. 2021; 27: 15071513.

[39] Sudre CH, Murray B, Varsavsky T, Graham MS, Penfold RS, Bowyer RC, et al. Attributes and predictors of long COVID. Nature Medicine. 2021; 27: 626-631.

[40] Rudski L, Januzzi JL, Rigolin VH, Bohula EA, Blankstein R, Patel AR, et al. Multimodality Imaging in Evaluation of Cardiovascular Complications in Patients with COVID-19: JACC Scientific Expert Panel. Journal of the American College of Cardiology. 2020; 76: 1345-1357.

[41] Dennis A, Wamil M, Alberts J, Oben J, Cuthbertson DJ, Wootton $\mathrm{D}$, et al. Multiorgan impairment in low-risk individuals with post-COVID-19 syndrome: a prospective, community-based study. BMJ Open. 2021; 11: e048391.

[42] Farshidfar F, Koleini N, Ardehali H. Cardiovascular complications of COVID-19. JCI Insight. 2021; 6

[43] Samavati L, Uhal BD. ACE2, Much More Than Just a Receptor for SARS-COV-2. Frontiers in Cellular and Infection Microbiology. 2020; 10: 317

[44] Wan Y, Shang J, Graham R, Baric RS, Li F. Receptor Recognition by the Novel Coronavirus from Wuhan: an Analysis Based on Decade-Long Structural Studies of SARS Coronavirus. Journal of Virology. 2020; 94

[45] Crook H, Raza S, Nowell J, Young M, Edison P. Long covidmechanisms, risk factors, and management. British Medical
Journal. 2021; 374: n1648

[46] Fang L, Karakiulakis G, Roth M. Antihypertensive drugs and risk of COVID-19? - Authors' reply. The Lancet Respiratory Medicine. 2020; 8: e32-e33.

[47] Brown JD. Antihypertensive drugs and risk of COVID-19? The Lancet Respiratory Medicine. 2020; 8: e28.

[48] Wang W, Zhao X, Wei W, Fan W, Gao K, He S, et al. Angiotensin-converting enzyme inhibitors (ACEI) or angiotensin receptor blockers (ARBs) may be safe for COVID-19 patients. BMC Infectious Diseases. 2021; 21: 114.

[49] Wu Z, Hu R, Zhang C, Ren W, Yu A, Zhou X. Elevation of plasma angiotensin II level is a potential pathogenesis for the critically ill COVID-19 patients. Critical Care. 2020; 24: 290.

[50] Tseng Y, Yang R, Lu T. Two hits to the renin-angiotensin system may play a key role in severe COVID-19. The Kaohsiung Journal of Medical Sciences. 2020; 36: 389-392.

[51] Ahnach M, Zbiri S, Nejjari S, Ousti F, Elkettani C. C-reactive protein as an early predictor of COVID-19 severity. Journal of Medical Biochemistry. 2020; 39: 500-507.

[52] Chen LYC, Hoiland RL, Stukas S, Wellington CL, Sekhon MS Confronting the controversy: interleukin-6 and the COVID-19 cytokine storm syndrome. European Respiratory Journal. 2020; 56: 2003006.

[53] Leisman DE, Ronner L, Pinotti R, Taylor MD, Sinha P, Calfee CS, et al. Cytokine elevation in severe and critical COVID19: a rapid systematic review, meta-analysis, and comparison with other inflammatory syndromes. The Lancet Respiratory Medicine. 2020; 8: 1233-1244.

[54] Smilowitz NR, Kunichoff D, Garshick M, Shah B, Pillinger M, Hochman JS, et al. C-reactive protein and clinical outcomes in patients with COVID-19. European Heart Journal. 2021; 42 2270-2279.

[55] Newman WH, Castresana MR, Webb JG, Wang Z. Cyclic AMP inhibits production of interleukin- 6 and migration in human vascular smooth muscle cells. The Journal of Surgical Research. 2003; 109: 57-61.

[56] Ciccone MM, Scicchitano P, Zito A, Cortese F, Boninfante B, Falcone VA, et al. Correlation between inflammatory markers of atherosclerosis and carotid intima-media thickness in Obstructive Sleep Apnea. Molecules. 2014; 19: 1651-1662.

[57] Herold T, Jurinovic V, Arnreich C, Lipworth BJ, Hellmuth JC, von Bergwelt-Baildon $\mathrm{M}$, et al. Elevated levels of IL-6 and CRP predict the need for mechanical ventilation in COVID-19. Journal of Allergy and Clinical Immunology. 2020; 146: 128136.e4.

[58] World Health Organization. WHO recommends lifesaving interleukin-6 receptor blockers for COVID19 and urges producers to join efforts to rapidly increase access, WHO. 2021. Available at: https: //www.who.int/news/item/06-07-2021-who-recommend s-life-saving-interleukin-6-receptor-blockers-for-covid-19-a nd-urges-producers-to-join-efforts-to-rapidly-increase-access (Accessed: 10 August 2021).

[59] Siemieniuk RA, Bartoszko JJ, Ge L, Zeraatkar D, Izcovich A Kum E, et al. Drug treatments for covid-19: living systematic review and network meta-analysis. British Medical Journal. 2020; 370: $\mathrm{m} 2980$

[60] Evans RA, Leavy OC, Richardson M, Elneima O, McAuley HJC, et al. Clinical characteristics with inflammation profiling of Long-COVID and association with one-year recovery following hospitalisation in the UK: a prospective observational study. medRxiv. 2021. (in press)

[61] Brosnahan SB, Jonkman AH, Kugler MC, Munger JS, Kaufman DA. COVID-19 and Respiratory System Disorders. Arteriosclerosis, Thrombosis, and Vascular Biology. 2020; 40: 2586-2597.

[62] Wang F, Kream RM, Stefano GB. Long-Term Respiratory and 
Neurological Sequelae of COVID-19. Medical Science Monitor. 2020; 26: e928996.

[63] Prata-Barbosa A, Lima-Setta F, Santos GRD, Lanziotti VS, de Castro REV, de Souza DC, et al. Is pleural effusion in COVID19 interstitial pneumonia related to in-hospital mortality? Italian Journal of Medicine. 2021; 96: 582-592.

[64] Zhu Z, Lian X, Su X, Wu W, Marraro GA, Zeng Y. From SARS and MERS to COVID-19: a brief summary and comparison of severe acute respiratory infections caused by three highly pathogenic human coronaviruses. Respiratory Research. 2020; 21: 224.

[65] Thomas M, Price OJ, Hull JH. Pulmonary function and COVID19. Current Opinion in Physiology. 2021; 21: 29-35.

[66] Froidure A, Mahsouli A, Liistro G, De Greef J, Belkhir L, Gérard $\mathrm{L}$, et al. Integrative respiratory follow-up of severe COVID-19 reveals common functional and lung imaging sequelae. Respiratory Medicine. 2021; 181: 106383.

[67] Cortés-Telles A, López-Romero S, Figueroa-Hurtado E, PouAguilar YN, Wong AW, Milne KM, et al. Pulmonary function and functional capacity in COVID-19 survivors with persistent dyspnoea. Respiratory Physiology \& Neurobiology. 2021; 288: 103644.

[68] Wu X, Liu X, Zhou Y, Yu H, Li R, Zhan Q, et al. 3-month, 6-month, 9-month, and 12-month respiratory outcomes in patients following COVID-19-related hospitalisation: a prospective study. The Lancet Respiratory Medicine. 2021; 9: 747-754.

[69] Evans RA, McAuley H, Harrison EM, Shikotra A, Singapuri A, Sereno M, et al. Physical, cognitive and mental health impacts of COVID-19 following hospitalisation - a multi-centre prospective cohort study. 2022; 10: e9.

[70] McDonald LT. Healing after COVID-19: are survivors at risk for pulmonary fibrosis? American Journal of Physiology-Lung Cellular and Molecular Physiology. 2021; 320: L257-L265.

[71] Zhang P, Li J, Liu H, Han N, Ju J, Kou Y, et al. Long-term bone and lung consequences associated with hospital-acquired severe acute respiratory syndrome: a 15 -year follow-up from a prospective cohort study. Bone Research. 2020; 8: 8 .

[72] Augustin M, Schommers P, Stecher M, Dewald F, Gieselmann $\mathrm{L}$, Gruell $\mathrm{H}$, et al. Post-COVID syndrome in non-hospitalised patients with COVID-19: a longitudinal prospective cohort study. The Lancet Regional Health - Europe. 2021; 6: 100122.

[73] Strasser B, Burtscher M. Burtscher, Survival of the fittest: $\mathrm{VO}(2) m a x$, a key predictor of longevity? Frontiers in Bioscience (Landmark Edition). 2018; 23: 1505-1516.

[74] Faghy MA, Sylvester KP, Cooper BG, Hull JH. Cardiopulmonary exercise testing in the COVID-19 endemic phase. British Journal of Anaesthesia. 2020; 125: 447-449.

[75] Arena R, Faghy MA. Cardiopulmonary exercise testing as a vital sign in patients recovering from COVID-19. Expert Review of Cardiovascular Therapy. 2021; 19: 877-880.

[76] Baratto C, Caravita S, Faini A, Perego GB, Senni M, Badano LP, et al. Impact of COVID-19 on exercise pathophysiology: a combined cardiopulmonary and echocardiographic exercise study. Journal of Applied Physiology. 2021; 130: 1470-1478.

[77] Rinaldo RF, Mondoni M, Parazzini EM, Pitari F, Brambilla E, Luraschi S, et al. Deconditioning as main mechanism of impaired exercise response in COVID-19 survivors. European Respiratory Journal. 2021; 58: 2100870.

[78] Singh J, Rahman SA, Ehtesham NZ, Hira S, Hasnain SE. SARS-CoV-2 variants of concern are emerging in India. Nature Medicine. 2021; 27: 1131-1133.

[79] Wagner PD. Determinants of maximal oxygen transport and utilization. Annual Review of Physiology. 1996; 58: 21-50.

[80] Wagner PD. Gas exchange and peripheral diffusion limitation. Medicine and Science in Sports and Exercise. 1992; 24: 54-58.

[81] Granata C, Jamnick NA, Bishop DJ. Principles of Exercise Pre- scription, and how they Influence Exercise-Induced Changes of Transcription Factors and other Regulators of Mitochondrial Biogenesis. Sports Medicine. 2018; 48: 1541-1559.

[82] Twomey R, DeMars J, Franklin K, Culos-Reed SN, Weatherald $\mathrm{J}$, Wrightson JG. Chronic fatigue and post-exertional malaise in people living with long COVID. medRxiv. 2021. (in press)

[83] Rutherford G, Manning P, Newton JL. Understanding Muscle Dysfunction in Chronic Fatigue Syndrome. Journal of Aging Research. 2016; 2016: 2497348.

[84] Gusnanto A, Earl KE, Sakellariou GK, Owens DJ, Lightfoot A, Fawcett SA, et al. Discriminatory cytokine profiles predict muscle function, fatigue and cognitive function in patients with Myalgic Encephalomyelitis/Chronic Fatigue Syndrome (ME/CFS). medRxiv. 2020. (in press)

[85] White PD, Nye KE, Pinching AJ, Yap TM, Power N, Vleck V, et al. Immunological Changes after both Exercise and Activity in Chronic Fatigue Syndrome. Journal of Chronic Fatigue Syndrome. 2004; 12: 51-66.

[86] Pan Y, Yu Z, Yuan Y, Han J, Wang Z, Chen H, et al. Alteration of Autonomic Nervous System Is Associated With Severity and Outcomes in Patients With COVID-19. Frontiers in Physiology. 2021; 12: 630038 .

[87] Komaroff AL, Lipkin WI. Insights from myalgic encephalomyelitis/chronic fatigue syndrome may help unravel the pathogenesis of postacute COVID-19 syndrome. Trends in Molecular Medicine. 2021; 27: 895-906.

[88] Sander LE, Garaude J. The mitochondrial respiratory chain: a metabolic rheostat of innate immune cell-mediated antibacterial responses. Mitochondrion. 2018; 41: 28-36.

[89] Burtscher J, Cappellano G, Omori A, Koshiba T, Millet GP. Mitochondria: in the Cross Fire of SARS-CoV-2 and Immunity. IScience. 2020; 23: 101631 .

[90] Tay MZ, Poh CM, Rénia L, MacAry PA, Ng LFP. The trinity of COVID-19: immunity, inflammation and intervention. Nature Reviews Immunology. 2020; 20: 363-374.

[91] Arena R, Bond S, Calvo IR, Lebowicz L, Ozemek C, Severin R, et al. Shelter from the cytokine storm: Healthy living is a vital preventative strategy in the COVID-19 era. Progress in Cardiovascular Diseases. 2021. (in press)

[92] Anand SK, Tikoo SK. Viruses as modulators of mitochondrial functions. Advances in Virology. 2013; 2013: 738794.

[93] Welch C, Greig C, Masud T, Wilson D, Jackson TA. COVID-19 and Acute Sarcopenia. Aging and Disease. 2020; 11: 1345.

[94] Morley JE. COVID-19 - the Long Road to Recovery. The Journal of Nutrition, Health \& Aging. 2020; 24: 917-919.

[95] NICE. COVID-19 rapid guideline: managing the long-term effects of COVID-19. 2021. Available at: https://www.nice.org.u k/guidance/ng188 (Accessed: 3 December 2021).

[96] Kingstone T, Taylor AK, O'Donnell CA, Atherton H, Blane DN, Chew-Graham CA. Finding the 'right' GP: a qualitative study of the experiences of people with long-COVID. BJGP Open. 2020; 4: bjgpopen $20 \times 101143$.

[97] Hayes LD, Ingram J, Sculthorpe NF. More Than 100 Persistent Symptoms of SARS-CoV-2 (Long COVID): A Scoping Review. Frontiers in Medicine. 2021; 8: 750378.

[98] Xiong Q, Xu M, Li J, Liu Y, Zhang J, Xu Y, et al. Clinical sequelae of COVID-19 survivors in Wuhan, China: a single-centre longitudinal study. Clinical Microbiology and Infection. 2021; 27: 89-95.

[99] Machado FVC, Meys R, Delbressine JM, Vaes AW, Goërtz YMJ, van Herck M, et al. Construct validity of the Post-COVID19 Functional Status Scale in adult subjects with COVID-19. Health and Quality of Life Outcomes. 2021; 19: 40.

[100] Jacobs LG, Gourna Paleoudis E, Lesky-Di Bari D, Nyirenda T, Friedman T, Gupta A, et al. Persistence of symptoms and quality of life at 35 days after hospitalization for COVID-19 infection. 
PLoS ONE. 2020; 15: e0243882.

[101] Townsend L, Dyer AH, Jones K, Dunne J, Mooney A, Gaffney $\mathrm{F}$, et al. Persistent fatigue following SARS-CoV-2 infection is common and independent of severity of initial infection. PLoS ONE. 2020; 15: e0240784

[102] Bellan M, Soddu D, Balbo PE, Baricich A, Zeppegno P, Avanzi GC, et al. Respiratory and Psychophysical Sequelae among Patients with COVID-19 Four Months after Hospital Discharge. JAMA Network Open. 2021; 4: e2036142.

[103] Stavem K, Ghanima W, Olsen MK, Gilboe HM, Einvik G. Persistent symptoms 1.5-6 months after COVID-19 in nonhospitalised subjects: a population-based cohort study. Thorax. 2021; 76: 405-407.

[104] van den Borst B, Peters JB, Brink M, Schoon Y, BleekerRovers CP, Schers H, et al. Comprehensive Health Assessment
3 Months after Recovery from Acute Coronavirus Disease 2019 (COVID-19). Clinical Infectious Diseases. 2021; 73: e1089.

[105] Taquet M, Dercon Q, Luciano S, Geddes JR, Husain M, Harrison PJ. Incidence, co-occurrence, and evolution of long-COVID features: A 6-month retrospective cohort study of 273,618 survivors of COVID-19. PLoS Medicine. 2021; 18: e1003773.

[106] Faghy MA, Arena R, Stoner L, Haraf RH, Josephson R, Hills $\mathrm{AP}$, et al. The need for exercise sciences and an integrated response to COVID-19: a position statement from the international HL-PIVOT network. Progress in Cardiovascular Diseases. 2021; 67: 2-10.

[107] Faghy MA, Ashton RE, Maden-Wilkinson TM, Copeland RJ, Bewick T, Smith A, et al. Integrated sports and respiratory medicine in the aftermath of COVID-19. The Lancet Respiratory Medicine. 2020; 8: 852. 